\title{
Experiment of a novel four-spherical intrauterine contraceptive device with nickel-titanium
}

\author{
Jian-Chun $\mathrm{Yu}^{1 \dagger}$, Mei-Hua Zhang ${ }^{1 \dagger}$, Ling $\mathrm{Yu}^{1 \dagger}$, Li-Ping Zhai ${ }^{2}$, \\ Xia Song ${ }^{1}$, Fang-Di Dong ${ }^{1}$ and Yi Qiu ${ }^{1 *}$ \\ ${ }^{1}$ Key Laboratory of Birth Regulation and Control Technology of National Health Commission of \\ China, Key Laboratory for Improving Birth Outcome Technique, Maternal and Child Health Care \\ Hospital of Shandong Province, 238 East Road of Jingshi, Jinan, Shandong 250014, People's \\ Republic of China \\ ${ }^{2}$ Shandong Provincial Institute of Control of Endemic Disease, East Road of Jingshi, Jinan, \\ Shandong 250014, People's Republic of China \\ †Authors contributed equally to this work
}

\section{Abstract}

The aim of this study was to develop a novel four-spherical intrauterine contraceptive device (4-SIUD) with nickel-titanium (Ni-Ti) for human, and to evaluate the contraceptive effect. The 4-SIUD composed of 4 mesh spheres and 5 support arms. The shape of 4-SIUD was like a "T". The height $(H)$, upper width (D) and thickness of the 4-SIUD for macaques were $0.8 \mathrm{~cm}, 0.5$ $\mathrm{cm}$ and $0.3 \mathrm{~cm}$, and for human were $4.5 \mathrm{~cm}, 4.0 \mathrm{~cm}$ and $0.8 \mathrm{~cm}$, respectively. The 4-SIUD was inserted into 5 macaques and pregnancy was not observed at 12 months. Three women used the 4-SIUD for 12 months, uterine perforations, expulsion, pain, and pelvic inflammatory did not occur. The results suggested that the 4-SIUD is appropriate for rhesus macaques and human use, and has a good contraceptive effect.
More Information

*Address for Correspondence: Yi Qiu, Maternal and Child Health Care Hospital of Shandong Province, 238 East Road of Jingshi, Jinan, Shandong 250014, People's Republic of China, Tel: 13964006672 ;

Email: qiuyi987@sina.com

Submitted: 08 October 2020

Approved: 19 October 2020

Published: 20 October 2020

How to cite this article: $Y u$ JC, Zhang MH, Yu L, Zhai LP, Song $X$, et al. Experiment of a novel four-spherical intrauterine contraceptive device with nickel-titanium. Clin J Obstet Gynecol. 2020; 3: 142-144.

DOI: 10.29328/journal.cjog.1001068

Copyright: @ 2020 Yu JC, et al. This is an open access article distributed under the Creative Commons Attribution License, which permits unrestricted use, distribution, and reproduction in any medium, provided the original work is properly cited.

Keywords: Four-spherical intrauterine device (4SIUD); Contraception; Rhesus macaques

Check for updates

OPEN ACCESS

\section{Introduction}

Although human reproduction is proceeding in an orderly manner, birth control has always been an important part of human reproduction. At present, intrauterine contraceptive devices (IUDs) are commonly used in women, especially in China. Inducing local inflammatory reaction in the endometrium is the major effect of all IUDs. The inflammatory response can be enhanced by Cu-IUDs. Pregnancy rate after $\mathrm{Cu}$ IUD removal is similar to women who have never used IUD, so this inflammatory response caused by $\mathrm{Cu}$ is only transitory $[1,2]$ and not linked to permanent fertility problems: the same after LNG-IUS removal [3]. On the other hand, the effect on menstrual pattern of Cu IUD is a real "side effect", this could be the plus point of this device. Not the same for that during LNG IUS, the amenorrhea rate is often used as a therapeutic issue of heavy menstrual bleeding [4]. The $\mathrm{Cu}(\mathrm{CuT380A})$ IUD is the only non-hormonal LARC device approved by the United States Food and Drug Administration (FDA) [5]. The $\mathrm{Cu}^{2+}$ of $\mathrm{Cu}$-IUD-releasing such as small T-shaped devices which made of flexible plastic, can kill sperm. In the present study, the frame of the new four-spherical intrauterine contraceptive device (4-SIUD) is made of nitinol wire and silicone rubber. The nitinol wire is nontoxic and widely used in clinical such as orthopedics, bone and cardiovascular stents. The nitinol frame was covered with silicone rubber, to prevent the 4-SIUD from adhering to the endometrium. The metal copper and progestin are not used in the 4-SIUD. These may avoid or decrease the side effect of copper and hormone IUDs. The shape of the new 4-SIUD's frame was four-spherical, which is different from two-dimensional structure such as the traditional single ring type, $\mathrm{T}$ type or other open structure. The novel 4-SIUD has the advantages of light weight, harmless to the body, and excellent in biocompatibility. We have reported that the main contraceptive mechanism effect of the three-dimensional reticular IUD (3-DRIUD) in rats, and observed that the larger the physical space occupied by the intrauterine device, the less the pregnancy [6]. The aim of our study was to explored the contraceptive effect and changes in endometrium of macaques and to design the novel 4-SIUD for women.

\section{Materials and methods}

Materials of the new 4-SIUD and inserter for rhesus macaques and human 
The frame of the 4-SIUD was composed of nitinol wire (with a diameter of $0.05 \mathrm{~mm}$ ) and covered with a layer of silicone rubber. The material of the inserter of the 4-SIUD for rhesus macaques and for human was stainless steel and plastic tube, respectively.

\section{Animals}

Rhesus macaques were from the Fujian Provincial Nonhuman Primate Animal Experimental Center. All procedures were performed in accordance with "Guidelines for the Care and Use of Experimental Animals in Fujian Province", and approved by the Animal Care and Use Committee of Fujian Provincial Institute for Family Planning Science and Technology. In December 2016, five adult female rhesus macaques were into the experiment. The license number of the Animal Care and Use was SYXK (Min) 2015-0007 and SCXK (Min) 2015-0002. All macaques were single cage (stainless steel) with standard feeding. The indoor temperature of the animal was $22 \sim 25^{\circ} \mathrm{C}$, the relative humidity was $60 \sim 70 \%$, artificial lighting was $12 \mathrm{~h} / \mathrm{d}$, and the air was ventilated.

\section{Surgical procedures}

The surgical procedures were carried out under sterile technique. Macaques were sedated with ketamine, atropine sulfate $(0.02 \mathrm{~mL} / \mathrm{kg}$ intramuscular injection) and ketamine hydrochloride (0.1-0.2 mL/kg intramuscular injection in a 50 $\mathrm{mg} / \mathrm{mL}$ aqueous solution), the abdominal regions were shaved and the animals were positioned in the supine position. The lower abdominal region was disinfected with $70 \%$ ethanol and iodine tincture and covered with sterilized drapes. Then surgical midline lower abdominal incision was performed and the uterus was exposed. The external dimensions of the uterus were measured with a sterilized caliper. A catheter was inserted into the uterus. The 4-SIUD was placed into the uterine cavity for 5 macaques. Then the incision of the uterus was sutured with absorbable sutures. Macaques received prophylactic antibiotics (Cefazolin, $30 \mathrm{mg} / \mathrm{kg}$ ).

\section{Treatment phase and ultrasonography}

On the $10^{\text {th }}$-day after operation, 5 female macaques were coupled with fertile male macaques (1:1) to observe the effect of contraception of the 4-SIUD. To check the uterus, 4-SIUD and pregnancy, an abdominal ultrasound was performed for 5 macaques every month. For ultrasonography, an X300PE (Siemens, Germany) machine with a $3.5-\mathrm{MHz}$ (VS 13-5, Siemens) probe was used.

After hysterectomy, the uterus was used for histology studies. Several cross-sections (about $2 \mathrm{~mm}$ thick) were cut freehand from the lumen to the myometrial border with a razor blade under stereomicrocope magnification.

\section{Results}

The shape and size of the 4-SIUD

The structure of the 4-SIUD was according to the size and shape of the rhesus macaque's and human's uterus. For rhesus macaques, the shape of the 4-SIUD was three-dimensional in nature and was a reticular grid. Its height $(\mathrm{H})$, upper width (D) and thickness were $1.0 \mathrm{~cm}, 0.6 \mathrm{~cm}$ and $0.4 \mathrm{~cm}$, respectively. The weight of the 4-SIUD was $0.018 \mathrm{~g}$. A layer of silicon-boron coupling agent was covered on the surface of the 4-SIUD, and finally multi-layer coating method was used with silica gel, and the 4-SIUD coated with silica gel was vulcanized. The 4-SIUD was placed in the external casing tube of the inserter. The inserter of the 4-SIUD was composed of an external casing tube (diameter $2.0 \mathrm{~mm}$ ) and an internal needle core (pushrod) (diameter $1.8 \mathrm{~mm}$ ).

For human, the 4-SIUD composed of 4 mesh spheres and 5 support arms. For human, the frame of the 4-SIUD was four sphere and T-like (Figure 1). The height (H), upper width (D) and thickness of the 4-SIUD for human were $4.5 \mathrm{~cm}, 4.0 \mathrm{~cm}$ and $0.8 \mathrm{~cm}$, respectively. Two spheres at both sides of the 4-SIUD were made of nickel-titanium alloy wire with diameter of 0.3 $\mathrm{cm}$, which can restore its designed shape at body temperature (37 degrees).

A strut made of $1.2-1.5 \mathrm{~cm}$ nitinol wire, with a diameter of $0.1 \mathrm{~cm}$, and the front end was connected with a $0.3 \mathrm{~cm}$ nitinol wire sphere. The middle part was the connecting rod between the support rod and the middle sphere (h $1.2 \sim 1.5 \mathrm{~cm})$. The middle sphere and the lower sphere were connected by nitinol wire $(2.0 \sim 2.5 \mathrm{~cm})$. The central ball of the four-spherical IUD was a $1.2 \mathrm{~cm}$ hollow nitinol wire spheroid. The lower end was a $0.3 \sim 0.4 \mathrm{~cm}$ nickel-titanium memory alloy and nano-copper hollow sphere.

The two sides of the 4-SIUD were braided by two 1.2-1.5 $\mathrm{cm}$ nickel wires, with a diameter of $0.2 \mathrm{~cm}$, and the front end was connected with a $0.3-\mathrm{cm}$ diameter nickel wire sphere. The middle part was the connecting rod between the support rod and the middle sphere $(\mathrm{h} 1.2 \sim 1.5 \mathrm{~cm})$. The middle ball and the lower ball were linked by nitinol wire $(2.0 \sim 2.5 \mathrm{~cm})$.

The 4-SIUD inserter was a cannula type, and the push rod of the placer was made of hard plastic material with a certain degree of hardness. The push rod had a scale to measure the depth of the uterine cavity. Push rod length $(\mathrm{H})$ was $20-25 \mathrm{~cm}$. The outer tube of the placer was a plastic tube with a diameter of $0.5 \mathrm{~cm}$ and was flexible (Figure 1 ).

\section{Pregnancy at 12 months}

The mean weight and mean age of 5 macaques were $6.3 \pm 1.2 \mathrm{~kg}$ and $122.9 \pm 1.7$ months, respectively. No pregnancy was found during placement of 4-SIUD.

Before placement the 4-SIUD, 6 types of commonly used IUD were excluded in 3 women at first month to 3 months. After placement of the 4-SIUD for 12 months, the 4-SIUD was in the uterus and no pregnancy was occurred. 

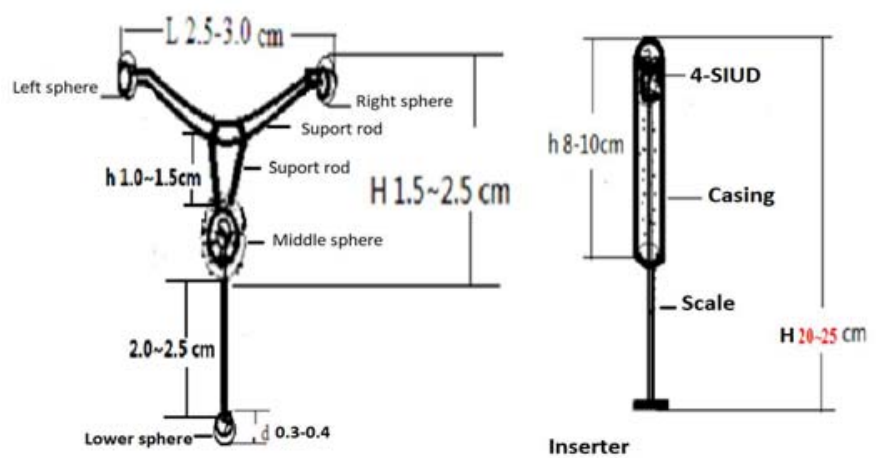

Figure 1: The four-spherical IUD and the inserter. Left, 4-SIUD. Right, the 4-SIUD was placed in the inserter.

\section{Discussion}

We designed the shape of the 4-SIUD by using nitinol wire, performed rhesus macaque experiments, and no pregnancy was found. For check whether pregnant, abdominal ultrasound was performed. Three women, who placement of 6 types of commonly used IUD were excluded, were successfully placed in the 4-IUD for 12 months and no pregnancy was found. The dimensional compatibility of the IUD or intrauterine system with the uterine cavity is very important. Correct installation of IUD or IUD system will reduce adverse effects and improve acceptability, and enhance the continuation of the IUD use [7]. Pain, erratic bleeding or menorrhagia and expulsion of IUDs may be caused by the size incompatibility. In the present study, the weight of the 3-DGIUD's frame was light (0.018 g). The shape of the 3-DGIUD was like a "T". Embryo implantation was interfered. Nitinol has a memory function, and can recover to the designed shape at body temperature. Therefore, the 4-SIUD has a good flexibility, may conform to the contraction and activity of the uterus, and may avoid uterine perforation. The central ball of the 4-SIUD can stabilize the IUD in the uterine cavity and interfere with embryo implantation. The lower end sphere with nano-copper hollow can automatically enter the inner orifice of the cervix. Nano-copper has a spermicidal effect. The first line of defence is set up at the inner orifice of the cervix. Contraceptive effect will be high, and the damage of copper ions to the endometrium will be reduced. The 4-SIUD was easy to place and take out. The two arms of the 4-SIUD were elastic and can stretch to the opening of the fallopian tubes on both sides of the uterus, and the spheres at both ends enter the opening of the fallopian tube and the uterus, which can prevent sperm from entering the fallopian tube and play a contraceptive effect. The 4-SIUD was a nickel-titanium memory alloy wire with a temperature shape memory function. It was a straight line at about 25 degrees at room temperature, and when it is placed in the uterine cavity environment (37 degrees) to restore the designed shape.

Wu, et al. reported that the LNG-IUS placed in 3 monkeys, expulsion of device was found in one monkey [8]. In human women, the rate of postpartum IUD expulsion varies from $1.9 \%$ to $29.7 \%$ which depending on [9-12]. while removal rates are $3.6 \%$ to $19.3 \%$ due to associate side effects (bleeding, pain and discharge) $[9,11]$.

\section{Conclusion}

The 4-SIUD was suitable for macaques and human, and had no permanency. The contraceptive effect was good.

\section{Funding}

The article is fully funded by "the National Key Research and Development Plan" with grant number: (2016YFC1000903).

\section{References}

1. Vree M. Lower hormone dosage with improved cycle control. Eur J Contracept Reprod Health Care. 2002; 7: 25-30.

PubMed: https://pubmed.ncbi.nlm.nih.gov/29243956/

2. Gupta BK, Gupta AN, Lyall S. Return of Fertility in Various Types of IUD Users. Int J Fertil. 1989; 34: 123-125.

PubMed: https://pubmed.ncbi.nlm.nih.gov/2565315/

3. Hassan MAM, Killick SR. Is Previous Use of Hormonal Contraception Associated With a Detrimental Effect on Subsequent Fecundity? Hum Reprod. 2004; 19: 344-51.

PubMed: https://pubmed.ncbi.nlm.nih.gov/14747178/

4. Grandi G, Farulla A, Sileo FG, Facchinetti F. Levonorgestrelreleasing Intra-Uterine Systems as Female Contraceptives. Exp Opin Pharmacother. 2018; 19: 677-686.

PubMed: https://pubmed.ncbi.nlm.nih.gov/29637798/

5. Sanders JN, Adkins DE, Kaur S, Storck K, Gawron LM, et al. Bleeding, cramping, and satisfaction among new copper IUD users: A prospective study. PLoS One. 2018; 13: e0199724.

PubMed: https://pubmed.ncbi.nlm.nih.gov/30403671

6. Qiu Y, Wang LG, Zhang MH, Zhang YP, Zhang AD, et al. A new experimental three-dimensional, reticular intrauterine device (3-DRIUD) composed of nitinol and silicone rubber. Contraception. 2013; 88: 31-36. PubMed: https://pubmed.ncbi.nlm.nih.gov/23218860/

7. Wildemeersch D, Hasskamp T, Nolte K, Jandi S, Pett A, et al. A multicenter study assessing uterine cavity width in over 400 nulliparous women seeking IUD insertion using $2 \mathrm{D}$ and $3 \mathrm{D}$ sonography. Eur J Obstet Gynecol Reprod Biol. 2016; 206: 232-238. PubMed: https://pubmed.ncbi.nlm.nih.gov/27768966/

8. Harrison-Woolrych M, Ashton J, Coulter D. Uterine perforation on intrauterine device insertion: is the incidence higher than previously reported? Contraception. 2003; 67: 53-56.

PubMed: https://pubmed.ncbi.nlm.nih.gov/12521659/

9. Wu C, Xia W, Wu X, Li R, Huang X, et al. Effect of domestically-made levonorgestrel-releasing intrauterine device on the endocrine system and menstruation in monkeys. J Tongji Med Univ. 1996; 16: 117-120. PubMed: https://pubmed.ncbi.nlm.nih.gov/9275705/

10. Makins A, Taghinejadi N, Sethi M, Machiyama K, Munganyizi P, et al FIGO postpartum intrauterine device initiative: Complication rates across six countries. Int J Gynaecol Obstet. 2018; 143 Suppl 1: 20-27. PubMed: https://pubmed.ncbi.nlm.nih.gov/30225873/

11. Jatlaoui TC, Whiteman MK, Jeng G, Tepper NK, Berry-Bibee E, et al Intrauterine Device Expulsion After Postpartum Placement: A Systematic Review and Meta-analysis. Obstet Gynecol. 2018; 132: 895-905

PubMed: https://www.ncbi.nlm.nih.gov/pmc/articles/PMC6549490/

12. Schnyer AN, Jensen JT, Edelman A, Han L. Do menstrual cups increase risk of IUD expulsion? A survey of self-reported IUD and menstrual hygiene product use in the United States. Eur J Contracept Reprod Health Care. 2019; 24: 368-372.

PubMed: https://pubmed.ncbi.nlm.nih.gov/31335218/ 